\title{
Propositions for a Resilient, Post-COVID-19 Future for the AEC Industry
}

\author{
Hala Nassereddine ${ }^{1 *}$, Kyung Wook Seo ${ }^{2 *}$, Zofia K. Rybkowski ${ }^{3}$, Christian Schranz ${ }^{4 *}$ and \\ Harald Urban ${ }^{4}$
}

${ }^{1}$ Department of Civil Engineering, University of Kentucky, Lexington, KY, United States, ${ }^{2}$ Department of Architecture and Built Environment, Northumbria University, Newcastle upon Tyne, United Kingdom, ${ }^{3}$ Dept. of Construction Science, College of Architecture, Texas A\&M University, College Station, TX, United States, ${ }^{4}$ Department of Civil Engineering, TU Wien, Austria

\section{OPEN ACCESS}

Edited by:

Hadi Sarvari,

Islamic Azad University, Iran

Reviewed by: Ke Chen,

Huazhong University of Science and

Technology, China

Alireza Valipour,

Islamic Azad University of Shiraz, Iran

*Correspondence:

Hala Nassereddine

hala.nassereddine@uky.edu

Kyung Wook Seo

kyung.seo@northumbria.ac.uk

Christian Schranz

christian.schranz@tuwien.ac.at

Specialty section:

This article was submitted to Construction Management, a section of the journal

Frontiers in Built Environment

Received: 28 March 2021 Accepted: 21 June 2021

Published: 08 July 2021

Citation:

Nassereddine $H$, Seo KW, RybkowskiZK, Schranz C and Urban H (2021) Propositions for a Resilient,

Post-COVID-19 Future for the AEC Industry.

Front. Built Environ. 7:687021. doi: 10.3389/fbuil.2021.687021
The coronavirus outbreak has challenged and continues to challenge every aspect of the supply chain within the AEC industry, forcing stakeholders to cope with increasing uncertainties and continuous change. The notion of resilience is especially salient now. While the need for the AEC industry to focus on resilience has been highlighted in recent articles, there is a need for a comprehensive discussion on what resilience means for the AEC industry and how companies can create built-in resilience. This paper takes the form of a high-level overview of where the industry is headed and aims to establish eleven propositions for a resilient, post-COVID-19 future, for practitioners working in the design and construction industry. Moreover, this paper proposes a 'decentralization of workforce and integration of data' model in which the established propositions are manifested to support a resilient AEC industry.

Keywords: resilience, AEC industry, post-COVID-19 pandemic, decentralization, data integration

\section{INTRODUCTION}

Henri Bergson, a philosopher and winner of the French Nobel Prize, is believed to be the first to use the term "living order" to highlight the idea that life is a continual process of unpredictable change. While businesses operating in the year 2020 have a defined past and present, their future is uncertain. The COVID-19 pandemic can be likened to a battle, challenging the continuity of businesses, in which practitioners in the Architecture, Engineering and Construction (AEC) industry have been forced to engage. The labor-intensive nature of the AEC industry makes it vulnerable to the COVID19 pandemic, and the knowledge, attitudes, and practices (KPA) of the stakeholders play a vital role in controlling the impacts of this pandemic (Zheng et al., 2020). Various articles have been written about the inefficiencies and chronic problems plaguing the AEC industry where design challenges, fragmentation, low productivity, low margins, cost and schedule overruns, labor shortages, wastage, unsafe working conditions, and miscommunication are commonplace (Bou Hatoum et al., 2020; El Jazzar et al., 2020a; El Jazzar et al., 2020b; Nassereddine et al., 2019, 2020a). The AEC industry is also more volatile-responding more acutely to economic crises and depressions than other sectors (The Fees Bureau, 2020). Between 1964 and 2019 in the United Kingdom, compared to the annual GDP, the construction market rose and fell $10 \%$ in response to three major economic crises (Figure 1). For architects, these economic downturns can be even more damaging-fluctuating by $50 \%$ or more, making architects one of the most vulnerable groups during a recession (Mirza, 2020). Unfavorable market environment can be initiated solely by economic instability, but when it is combined with natural disasters or pandemics, the impact on the industry can be devastating. A 2018 AIA survey 


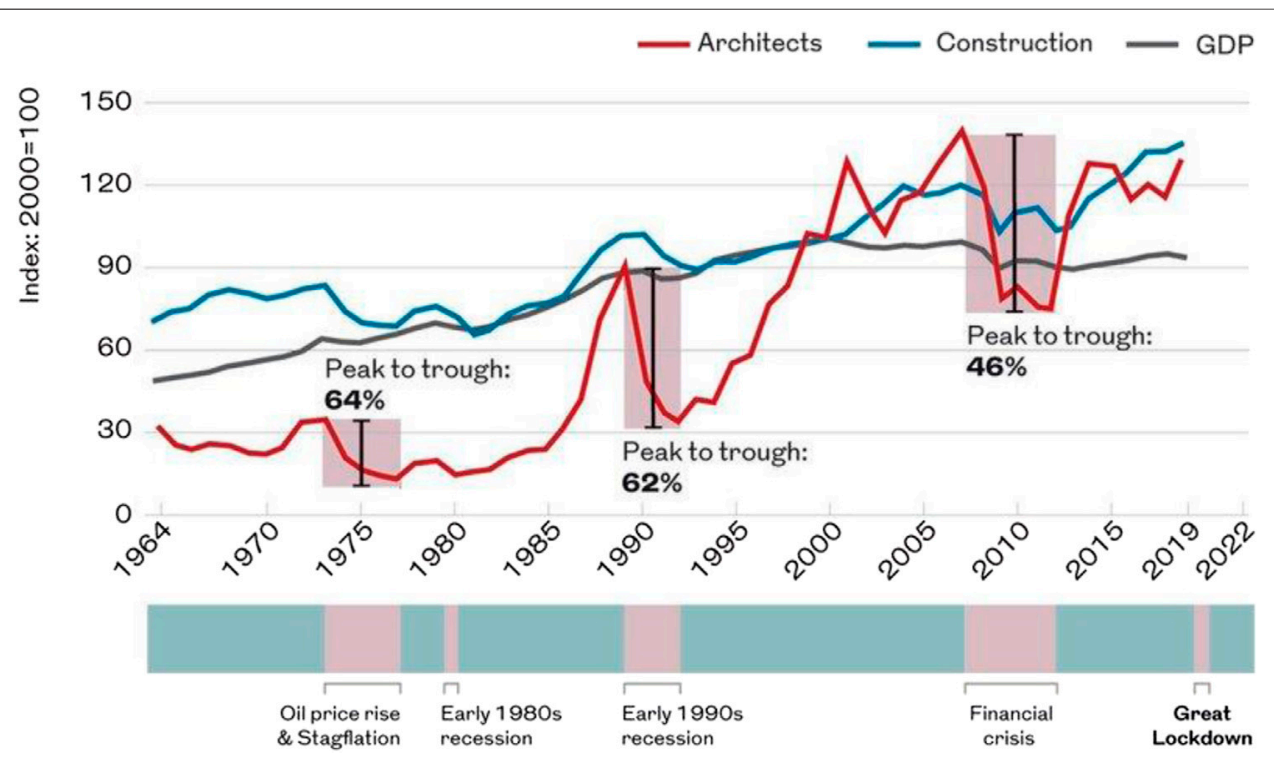

FIGURE 1 | Architects' workloads and construction output compared with annual GDP. (C) The Fees Bureau Reprinted from Mirza (2020).

found that only $22 \%$ of smaller architectural design firms in the United States with 1-19 employees had equipped themselves with a contingency plan in the event of business disruption, compared to $72 \%$ of larger firms (AIA, 2020). The impact of the current COVID-19 pandemic however is unprecedented in modern history. It has been a scenario for which few current business leaders had properly prepared (McKinsey and Company, 2020a). Alsharef et al. (2021) provided a holistic understanding of the early impacts of the COVID-19 pandemic on the United States industry and identified the following major adverse impacts: disparity across states on whether construction work is essential or non-essential, material delivery delays and shortage of material, delays in inspections and securing permits, reduction in efficiency and productivity rates, emergence of COVID-19 safety concerns, expected increase in disputes, litigation, and claims, increase in demand from local suppliers and manufacturers, and transition to remote working.

Although a crisis, the COVID-19 pandemic has also served as a wake-up call for the industry as it has brought to the surface longstanding problems and highlighted areas in urgent need of reform and improvement. An important question arises as to how to thrive in a volatile, uncertain, complex, and ambiguous environment. Similar to how boxers demonstrate resilience in the ring, the AEC industry must be resilient enough to win a fight during times of unexpected crises. Wilkinson et al. (2016) noted that the construction sector needs to be resilient to recover more quickly from crises. With the coronavirus outbreak declared as a global crisis and the disruption it has generated, building resilience into the AEC industry is sorely needed (Cheshmehzangi 2021). The notion of resilience is especially salient now as external conditions around the world are experiencing increasing bouts of change.
A question then arises about how to build resilience into the AEC industry. Kim (1998) analyzed the Hyundai Motor Company and noted that the company proactively constructs internal team crises as a strategy to foster creativity, expedite learning, and elevate the adaptive capacity of both teams and organization. In other words, to prepare for uncertain external assaults to their systems, Hyundai created artificial crises to identify and improve areas of weakness in their teams and business processes. Unlike Hyundai's exercises, the emergence of COVID-19 was not artificially orchestrated to reveal weaknesses in the AEC industry. However, the pandemic can be viewed through a similar lens-i.e., as an opportunity to identify how the AEC industry can be made more resilient in preparation for additional emerging challenges, such as climate change. It has been observed that resilient organizations successfully adapted to COVID-19 challenges (Chong et al., 2020). In an interview with Zawya Projects, the Chairman and Chief Executive Officer of the global automation giant Rockwell Automation, Blake Moret, stated that "the coronavirus pandemic has forced companies to sharpen their focus on resilience, agility, and sustainability" (Zawya, 2021). Moret added that resilience typically involves remote operations, traceability, and movement of operations to different locations in times of crises (Zawya, 2021). A recent article in Engineering News Record highlighted that resilience within the construction industry is clear in how construction participants met the challenges imposed by the pandemic (Rubin et al., 2021).

Researchers argue that resilient organizations must use technological advancements in Information and Communications Technology (ICT), Artificial Intelligence 
TABLE 1 | Eleven major trends for the future of the AEC industry post-Covid-19.

Trends post-COVID-19 pandemic

Portfolio diversification

Collaborative contracting methods

Industrialization

Circular economy

Remote working

Integrated design management using BIM

Staffing and skills training

Reversible building design

Augmented reality

Automation and $3 \mathrm{D}$ printing

Lean construction
References
Domingos et al. (2021); McKinsey and Company (2020a); Rajabi and Bheiry 2020; Wood (2021)

Barbosa et al. (2020); MCAA (2020); Ramya (2020); Wong et al. (2020)

Cheshmehzangi (2021); McKinsey and Company (2020c); Gatheeshgar et al. (2021)

Dokter et al. (2021); Ibn-Mohammed et al. (2021); Cetin et al. (2021); Munaro et al. (2020)

Green (2020); McKinsey and Company (2020b); Juhasz et al. (2020); Birkinshaw et al. (2020)

NBS (2020); Luo et al. (2020); Leon et al. (2021)

AIA (2020); RIBA (2020c); Harrouk (2020); International Labour Organization (2021)

Souza (2021); Cutieru (2020); Durmisevic (2020)

Adhikari and Poudyal (2021)a; b; Build Media Group (2021); Ebekozien and Aigbavboa (2021); Heiskanen (2020)

Wallett (2021); Zhu et al. (2021); Byrne (2020)

McKinsey and Company (2020c)
(AI), and automation to increase collaboration and cooperation, both vertically and horizontally (Butler, 2018; Kamble et al., 2018; Belhadi et al., 2021). Additionally, in a recently published report in Trimble Buildings (2020), construction practitioners stated that a successful project team is one that can demonstrate an ability to pivot and respond to changes imposed by external requirements, such as a shutdown. The report also emphasized the role COVID-19 played in catalyzing innovation in construction by advancing technologies such as robotics and augmented reality. In another article, construction practitioners noted that adoption of technology by the industry could serve as a silver lining for the pandemic (Rubin et al., 2021). Finally, because relationships serve as the heartbeat of a construction project and the organizations that design and build them, the resiliency of project team members plays a vital role in supporting a resilient construction project (Courtemanche, 2020).

While the need to be resilient going forward has been highlighted by construction researchers and practitioners, there are limited discussions on what resilience actually means to the AEC industry and how it can be built to support the growth of its members in a post-pandemic world. A review of articles that discuss the future of the AEC industry post-COVID-19 between 2020 and 2021 resulted in identification of 11 major trends that can allow the AEC industry to rebound post-pandemic (Table 1).

Building on existing work, this paper adopts a definition of resilience for the AEC industry, discusses how resilience can be strategically embedded into AEC organizations, and investigates trends that support resilience in design and construction.

\section{RESILIENCE THROUGH STRATEGY}

One of the original definitions of resilience was proposed by Holling (1973) and summarized by Angeler and Allen (2016) as "the amount of disturbance that a system can withstand before it shifts into an alternative stable state" (p. 617). Of note is the focus on a system shifting to an "alternative stable state." This is quite different from definitions of resilience typically put forth in architecture and engineering literature and by professional societies, where resilience instead takes the form of risk mitigation (Hosseini et al., 2016; Kurth et al., 2019). For example, the AIA' Architect's Guide to Business Continuity (AIA, 2020) includes a checklist for risk mitigation so a firm can continue to function as usual in the event of business disruption. Although a useful guide, this approach assumes that after a threat has passed, the external environment will return to the way it was before. In a similar vein, for the engineering community, Keenan (2020) wrote: "In its most simplified distillation, 'engineering' resilience (and to a large extent 'disaster' resilience) speaks to the elastic and reversionary capacities of a system to return to pre-stimulus level of operational performance and material quality, which may ultimately lead to adaptive and maladaptive outcomes ... " (p. 217).

Underlying these conventional approaches to resilience is an assumption that the external environment exists within a steady state to which disrupted systems can return, and therefore any disturbances must be mitigated. Yet as the recent COVID-19 pandemic has shown us-as well as foreboding upcoming shifts in the earth's climate-the definition of resilience that the AEC community would do well to consider instead is that which was originally proposed by Holling (1973). In this approach, resilience is less about risk mitigation that enables elastically returning to a state that was before, but more about adaptive capacity-i.e., the ability to adapt to a world that is permanently under transformation, where both social and physical elements are mobilized (Nelson et al., 2007; Angeler and Allen, 2016). This type of adaptation is, in fact, the way species of organisms have evolved and continue to evolve in order to survive dramatic upheavals to their ecosystems (Miller and Spoolman, 2009). The built environment and we-the human beings who construct it-exist within these environmental ecosystems. We would do well to observe and even mimic how natural organisms have developed these adaptive capacities.

\section{Diversifying Portfolio}

Designers, contractors, and subcontractors are service-provider organizations that bring expertise in order to work toward a common goal to satisfy stated owner needs for a construction project (Al Sayegh, 2010). It is typical, for example, for an architectural practice to possess a clear set of expertise related to the building typologies it can best deliver. The portfolio 
strategy of each service-provider needs to be aligned with the strategy of the owners that they serve to ensure the needs of the owners are ultimately being met. The economic downturn caused by the pandemic has forced some owners to hold off on moving forward with new construction projects and to adjust their strategies (Jones, 2020). The level and severity of the pandemic varied across sectors and owners, making COVID-19 a major risk management factor for construction service-providers to consider and assess (Rajabi and Bheiry, 2020).

Events such as the current economic recession caused by the pandemic brings an opportunity for construction serviceproviders to pause and reflect on their ability to adapt to possible future scenarios. An organization's existing portfolio which targets specific sectors and types of work should be reevaluated through a resiliency lens with an aim to predict and prepare for survival and continuity of its business. Depending on the type of recession, demand for some types of projects may dwindle, while others may rise. For example, during the COVID19 pandemic, commercial sector projects were hit hard, but there was also a growing number of projects in the interior design sector (Laing and Moss, 2020). While the landscape of owners is changing, construction service-providers need to carefully assess their portfolios to mitigate risk, remain competitive, and grow. Portfolio diversification is a competitive strategy that is more profitable and stable than a homogeneous portfolio (Markowitz, 1959). Diversifying an organization's portfolio is also considered by some as the single most important factor ensuring business resilience (RIBA, 2020b). Kim and Reinschmidt (2011) analyzed 400 large contractors in the U.S. and concluded that a diversification strategy and managing business risks and firm growth are directly correlated and contractors that diversify their portfolio are able to reduce market risks and grow as a firm. Diversification practices need to include sectors and services that are affected differently by political and economic landscapes. For example, public and private sectors are typically on different spending cycles which provide opportunities during crises (AIA, 2020). As important as diversifying scope of work is diversifying project geographies (AIA, 2020). Global downturns can have varying impacts on different regions of the world, and therefore being prepared to explore new markets outside an impacted region can serve as a powerful contingency plan during a crisis.

\section{Collaborative Contracting Methods}

Creating a business relationship with a high degree of resilience is essential for forming long and stable bonds between companies (Ojansivu and Hermes, 2019). Myer (2020) added that resilience in the face of the pandemic was rooted in the strength of the relationships between construction stakeholders. Additionally, a Harvard Business Review article discovered that resilient teams tend to have members that are able to resolve conflicts, collectively believe that they can effectively complete their tasks, and have a shared understanding of their roles and responsibilities (Kirkman et al., 2019).

The traditional project delivery system of design-bid-build is known to inhibit coordination, limit cooperation and innovation, and promote the reward of one stakeholder at the expense of others. By contrast, Integrated Project Delivery (IPD) emerged as an innovative delivery system that challenges the legacy of the AEC industry (Matthews and Howell, 2005). The American Institute of Architects (AIA) defines IPD as "a project delivery approach that integrates people, systems, business structures and practices into a process that collaboratively harnesses the talents and insights of all participants to optimize project results, increase value to the owner, reduce waste, and maximize efficiency through all phases of design, fabrication, and construction" (AIA, 2007, p. 2). The launch and implementation of IPD have revolutionized the way construction projects are being delivered by promoting communication, collaboration, trust, and transparency among the construction owner, designer, contractor, and subcontractors. The benefits of IPD were exemplified during the pandemic where stakeholders were required to work collectively and collaboratively to address associated challenges and ensure proper delivery of projects. Southland Industries stated that the use of IPD on the Penn Medicine Patient Pavilion allowed the construction project team to reduce the construction schedule for a portion of the new hospital tower in University City, Pennsylvania, by 15 months, to better prepare the facility for the potential influx of COVID-19 cases (MCAA, 2020).

\section{Industrialized Construction}

Offsite prefabrication and modularization enjoy a long tradition of working to: reduce waste and carbon emissions; create parallel coordination between onsite and offsite works; and enhance quality control (Jaillon et al., 2009; Luo et al., 2020). By industrializing building systems, these methods can simplify the process of design and construction without having to recreate it for each project. They address principles such as facilitating "design for deconstruction" by generating building systems based on the concept of IFD, i.e., industrialised, flexible and demountable (Crowther, 2005; Jaillon and Poon, 2014). Moreover, it is not only for the benefit of the environment that prefabrication and modularization can contribute. Tokazhanov et al. (2020) suggested that the COVID-19 pandemic might have a significant impact on construction jobsites where modular construction could gain more momentum. During the global COVID-19 lockdown, the flexibility of interior spaces became a major concern for a range of building types, as they required occupants to adapt to the way spaces were used, creating a new normal. Clients of future architectural projects are likely to demand a building program that is flexible enough to accommodate multiple scenarios of use. Strategies include industrialization of building components and systems, using prefabrication and modularization, and enabling a cost-effective construction of buildings where subsystems can be easily dismantled and replaced. For this, designers needed to prepare themselves to be able to coordinate their design with constructors. Additionally, with more emphasis placed on the need to drive efficiency, accelerate projects and overcome schedule overruns, and enhance the focus on worker safety, contractors have been moving toward modularization (Meisels, 2020; Cheshmehzangi, 2021). The need to practice social 


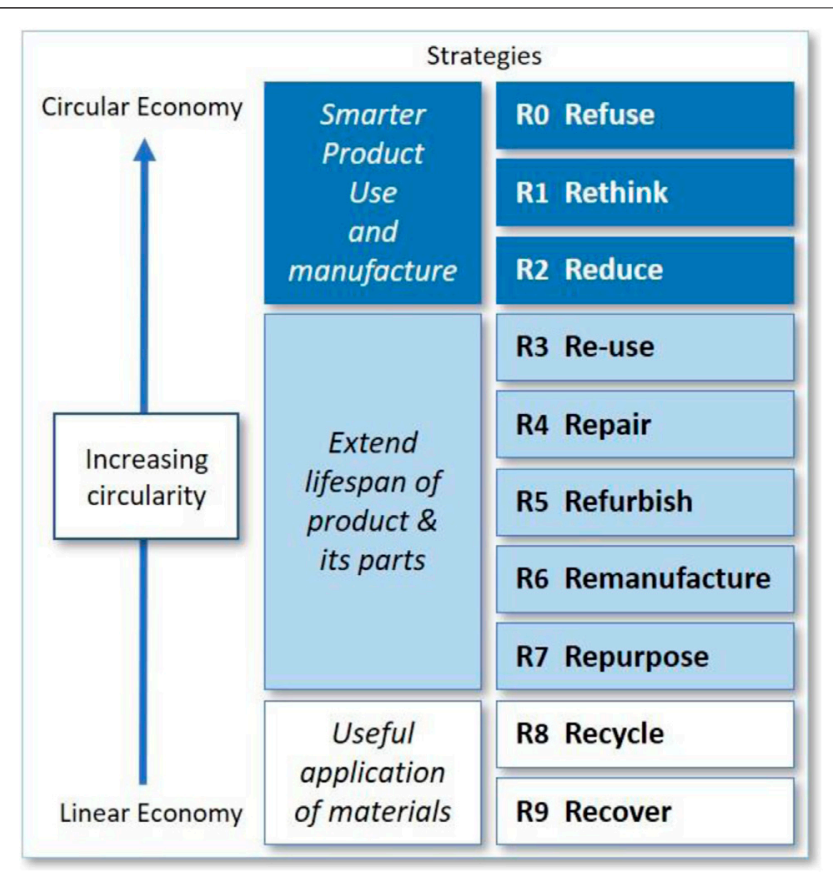

FIGURE 2 | Circularity strategies within the production chain, in order of priority. Adapted from Potting et al. (2017), fig. 1, p. 5.

distancing on a jobsite also makes a strong case to leverage modular construction. Moreover, as the construction industry increasingly faces an aging workforce and shortage of skilled labor, modularization offers contractors the opportunity to drive improvements by reducing on-site construction and increasing off-site construction methods that allow for quicker and more efficient work with reduced need for skilled labor (Astrachan, 2020). Providing contractors with the ability to improve efficiency, enhance safety, improve quality, increase productivity, reduce costs, and shorten schedules will enable contractors to combat unprecedented perils with resilience.

\section{Innovative Business Models in Circular Economy}

A new ethos for design and construction is emerging. Alongside resilience in management outlined above, architects, engineers, and constructors need to reposition themselves in the postpandemic world economy where social values and priorities in business are rapidly changing. Future-oriented design approaches using advanced concepts such as circular economy and reverse construction technology will become a more critical issue in the process of bidding for new projects. These will help brand and promote business in an increasingly competitive and environmentally conscious global market during and after economic and environmental crises. As value engineering becomes more vital in the future of the AEC industry, design and construction process need to be upgraded for cost-effective solutions without compromising quality by adopting resilient strategies (Lowery et al., 2011).
The emerging paradigm of a circular economy represents both a challenge and an opportunity for the design and construction industry. By re-adjusting the way projects are implemented, businesses can become more viable as well as profitable in an increasingly competitive and volatile market. The circular economy (CE) is an overarching concept still in its infancy in AEC industry. While research in the field of CE is growing, it is still in a phase of exploration without empirical validation and therefore further effort is needed to adapt it to the practices of design and construction (Munaro et al., 2020). Pioneering projects such as BAMB (Building As Material Bank) have been initiated by the $\mathrm{EU}$ to find solutions to preserve the value of building materials by using the concept of material passports and reversible building design (Debacker and Manshoven, 2016). EPA (United States Environmental Protection Agency) has been promoting the concept of CE by providing best practices and manuals for Design for Deconstruction (DfD) and recycling of C\&D (construction and demolition) materials. The current focus of the AEC industry however lies in the recycling of existing waste materials for new building structures (Dokter et al., 2021). Nevertheless, within the whole range of circularity strategies for the production chain suggested by PBL Netherlands Environmental Assessment Agency (Figure 2), recycling belongs to lower levels of priority (Potting et al., 2017). Without a systematic industrial effort to increase recycling as a priority and update material inventory, however, even basic levels of recycling cannot be made economically viable (Kozminska, 2019). Considering the industry's impact on waste generation (46\% in the EU) and global energy emissions (39\%), the current global movement toward it will soon impose political and economic imperatives to embrace it, especially in a post-pandemic landscape (Cetin et al., 2021).

\section{RESILIENCE THROUGH DESIGN}

During COVID-19, many practices in the United States and Europe were forced to shift their workforce base from offices to homes in very short notice with insufficient preparation. A disaster assistance manual for architects was published by the AIA years before the pandemic, suggesting an emergency management cycle, i.e., prepardness, response, recovery and mitigation (AIA, 2017). Because of the magnitude of disruption caused by COVID-19, a majority of practices were forced to immediately deal with the response phase with little help from an existing protocol of preparedness. The pandemic has triggered a paradigm shift to a new mode of working to create a more sustainable future for design practices. Since the beginning of the pandemic, various contingency guidelines and reports have been published by experts and professional groups, including by two influential architects' associations, the AIA and the Royal Institute of British Architects (RIBA). These guidelines provide recommendations for a wide variety of concerns for businesses such as insurance, contracts, facilities management and client relationships. The following sections will explore resilience as it relates to the human aspect of a business, focusing on the concept 


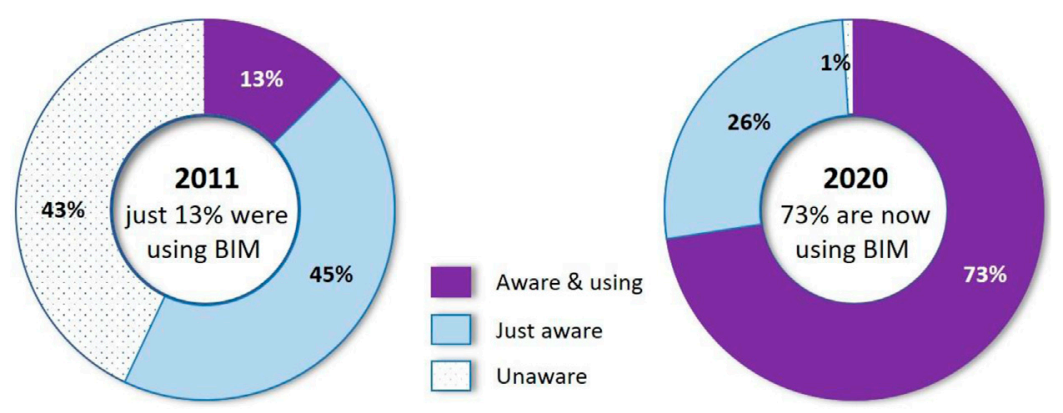

FIGURE 3 | BIM awareness and use-2011 vs 2020. Adapted from NBS (2020), p. 16.

within the workforce and its attendant workflows which are key elements for the survival and continuity of post-pandemic practices. By way of example of how the pandemic affected one arm of the AEC industry, the following sections will especially focus on architects.

\section{Remote Working}

According to a 2019 survey for RIBA, only 7\% of architects worked full time from home and $21 \%$ regularly worked from home of which $80 \%$ were sole practitioners (Buxton, 2020). This implied a tendency that flexible working from home could be easily adopted by either single-person practices or large practices, while mid-sized practices without an in-house technology team would be less prone to do so. During the COVID-19 lockdown, however, practices of all sizes were involuntarily forced to embrace remote working. Many found it intuitively easy to shift to remote working, and this dramatically changed worker attitudes toward it (Morris, 2021). Recent polls by The Economist (2020) suggest that across industries in the United Kingdom, twothirds of employees would like to continue working from home and only $8 \%$ wanted to return to the office full-time. It is predicted that office working will not disappear-but office environments will need reduced capacity, greater functionality, and require to be situated in better locations (Green, 2020). To make remote working a new normal in a post-COVID environment, two ICT requirements need to be in place. Firstly, remotely accessible data must be secure and there needs to be literacy by users about it. To enable this, it is crucial to provide a single or possibly multiple data storage points, and office servers or clouds where all digital resources including project data can be stored and accessed remotely through a secure validation system (AIA 2020; RIBA 2020a). Secondly, key IT equipment needs to be portable with a range of reliable software that can fully support collaborative online design and remote meetings and approval processes. These remote technologies and their attendant software systems have been available in the market for decades but the COVID-19 pandemic served as a catalyst to expand existing markets and accelerate competition for faster adoption of technology. To facilitate and embrace this shift to a remote working culture, it is important to recruit IT specialists for cyber security and to educate employees about the most effective ways to work remotely (AIA 2020).
Integrated Design Management Using BIM

In the context of contemporary construction projects which have become increasingly complex and difficult to manage, adoption of Building Information Modelling (BIM) has become a major agenda item in the industry in recent decades to help resolve issues of communication between stakeholders (Clough et al., 2008). It is a method of managing building design and project data in a digital format throughout a building's life-cycle (Succar, 2009). Knowing the benefits of reduced transaction costs and operational errors, many governments and local authorities are now making it mandatory to use BIM for projects. The United States adopted BIM as a requirement for the approval of all major projects since 2007. The United Kingdom has set a series of five-year plans to achieve a set target for BIM adoption (Hamma-adama and Kouider, 2019). A BIM survey in 2020 revealed that in the past 10 years, the use of BIM made a substantial leap from 13 to $73 \%$ in the United Kingdom design and construction sectors (Figure 3; NBS, 2020).

It has been a widespread perception in the building industry that BIM can generate benefits for large high-profile projects, but not for smaller projects. This perception however is changing, especially for those who experienced BIM's ability to significantly reduce risk and increase productivity (NBS, 2020). Since the beginning of the Covid-19 pandemic, the benefit of adopting BIM for remote construction projects is receiving increased attention. Architectural design is an intricate process linking five work themes, namely: thinking, creating, collecting, connecting, and correcting. BIM can generate meaningful benefits to each theme by creating shared understanding between stakeholders working in different locations (Arayici et al., 2012). This shared understanding can be maximized by the use of $3 \mathrm{D}$ models in $\mathrm{BIM}$ that can in turn generate $3 \mathrm{D}$ prints, animations, and virtual reality (Arayici et al., 2012).

\section{Resilience in Staffing and Skills Training}

One of the key issues of design management in times of business disruption is maintaining or stabilizing the work force. Stakeholders of the AEC workforce typically include teams and individuals of a firm but also contractors and suppliers outside, as well as collaborating practices. The AIA guide suggests building in redundancy for possible disruption caused by natural and human-made hazards which includes creating 
multiple points of contact, cross-training employees on tasks, developing succession and transition plans, and creating a culture of collaboration within the firm (AIA, 2020). RIBA also recommends that practices, especially smaller ones, pool resources and produce joint bids to win new work when an economy slows. If they can liaise with other professional firms such as those specializing in interior design and engineering, organizations can create a convenient one-stop-shop for clients and generate economically viable solutions starting at an early stage (RIBA, 2020c).

In addition to embracing and undertaking the design management strategies described above, it is an essential precondition to deliver knowledge and skills training for employees. This should be done as a part of a preparedness program when a business is running in normal conditions, to be able to reduce the risk of business disruption and help protect profits (Harrouk, 2020). Educating staff members on how to use software for remote working, generative design, simulation for fabrication, 3D printing, and how to integrate these functionalities using BIM is a crucial first step to completing the emergency management cycle of "preparedness, response, recovery and mitigation" recommended by the AIA (2017). Meanwhile, architects need to absorb advanced professional knowledge of future-oriented product design concepts such as circular economy, adaptive reuse, prefabrication, modular construction, and reverse construction technology. These emerging concepts are expected to soon play a crucial role within the next ten to twenty years, and are needed to compete effectively in the market, due to foreseeable environmental challenges such as climate change and resource depletion. The RIBA Code of Practice set out that practices should continuously improve their professional knowledge and skills for the "benefit of the public interest, those commissioning services, the profession and themselves" (RIBA, 2019, p. 9).

\section{Reversible Building Design}

As demolition generates up to $50 \%$ of total material waste worldwide, reducing waste by recycling materials at the end of the lifecycle of a building has become an important agenda for the AEC industry (Kibert 2008). However, rates of recycling are still low due to conventional construction methods that do not consider ways to dismantle materials during demolition (Potting et al., 2017). To shift this paradigm from recycling to reuse, it is necessary to develop reverse construction technologies to properly deconstruct buildings rather than to demolish them. For the successful recovery of materials during deconstruction, it is a crucial first step for design practices to develop technologies for Design for Deconstruction (DfD) or Reversible Building Design. There are barriers, such as existing standards and codes that do not provide clear guides regarding the use of recycled materials, or that overly regulate this practice, making it cost-prohibitive; but the potential advantage of adopting reversible building design is evident. In addition to making building components reusable, it also facilitates repair, refitting, or adaptively reusing a building for a substantially reduced cost (Souza, 2021). The EU project BAMB (Building as Material Bank) and the EPA (the United States Environmental Protection Agency) have supported benefits of this approach with examples of good practices. Reversible Building Design not only protects the environment but also introduces new business models for the whole building industry and creates new services and jobs for the stakeholders (Debacker and Manshoven, 2016). Concepts such as creating material passports can be adopted to facilitate this process from the design phase for recording and tracing building materials, and this can create opportunities for emerging professional roles such as "digital architect" and "building digitizer" (Debacker and Manshoven, 2016).

\section{RESILIENCE THROUGH CONSTRUCTION}

Developing a resilient organization and workforce is crucial to competing in the marketplace (Wang et al., 2014b; Cooke et al., 2020). Faced with disruptions and discontinuities, construction projects must be adaptable. Changes cannot be avoided on a construction project; therefore, it is important to embrace uncertainty and build in resilience to prepare project team members to adapt and therefore support the continuity of operations (Desai, 2012).

Sharing information and knowledge among various team members is essential to carrying out a project. The more complex the project, the more rich and diverse information becomes. When faced with changes and challenges, allowing project team members to access the right information at the right time to make informed decisions is crucial. Fulco et al. (2019) highlighted the importance of facilitating knowledge acquisition to face emerging problems and build in resilient thinking. While information sharing is key to a successful construction project implementation, the reality of the construction industry is that it embodies loss, attenuation, and separation of information when that information is used, transferred, and shared; these challenges have been well documented in construction (Zhang and Van Luttervelt, 2011). Researchers noted that ICTs help to build resilience into the AEC industry by leveraging information exchange, especially in a turbulent environment (Fulco et al., 2019). With rapid advances in emerging technologies and influenced by the fourth industrial revolution known as Industry 4.0, Construction 4.0 emerged as a new Frontier for gaining a competitive edge in the AEC industry (El Jazzar et al., 2020b). The underlying principle of Construction 4.0 is to enable the full integration of people, processes, and machines throughout the project lifecycle (Klinc and Turk, 2019; Sawhney et al., 2020). Ralston and Blackhurst (2020) noted that Industry 4.0 holds promise to enhance the resilience of organizations to disruptions. While the AEC industry had been showing an increased interest in Construction 4.0 pre-COVID-19, it would not be an overstatement to say that the pandemic has intensified this interest (Snyder, 2020). For example, the pandemic has forced companies to work remotely to protect their employees. Araya (2021) presented an agent-based approach to model the spread with of COVID-19 and showed that interactions among construction workers play a key role, forcing the reduction of interactions. Although most on-site work cannot currently be 


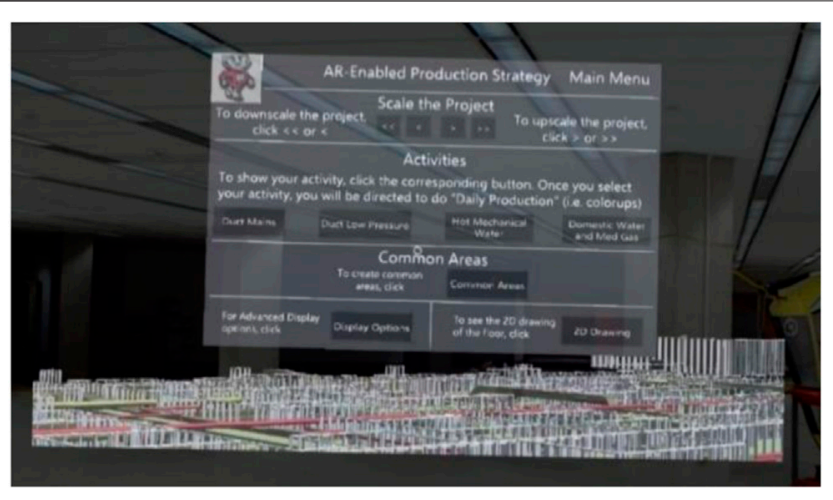

FIGURE 4 | User's First View of the AR-Enabled PSP. Reprinted from Nassereddine (2019), fig. 65, p. 213.

done remotely, some work can already be shifted from the construction site to a company's headquarters, or even to employee home offices, leading to a reduction in physical interactions. Technologies emerging from the fourth industrial revolution can be very helpful for this transition, especially by enhancing compliance with possible COVID-19 rules on the construction site (Ebekozien and Aigbavboa, 2021). In the context of the construction industry, these forms of technology are often categorized as Construction 4.0 (Klinc and Turk, 2019; Sawhney et al., 2020) and include, for example: building information modeling (BIM), augmented reality (AR), virtual reality (VR), robotics, 3D printing, artificial intelligence (AI), and drones. Cheshmehzangi (2021) named the push for information-based construction management methods as a future developmental change. Construction 4.0 technologies support this change. Most especially, the combination of BIM with augmented reality (AR) improves access to information on a construction site (Wang et al., 2014a).

\section{Augmented Reality}

Adapting to change is essential for maintaining continuity during disruptions. Construction workers need to be ready to pivot and adjust their practices to respond to change. When the coronavirus wave reached construction projects, workers needed to find alternatives to perform their work while simultaneously contending with public health concerns and safety standards established by regulators and their companies. Technologies that enable remote collaboration, and that support faster knowledge exchange and distribution are key. One Construction 4.0 technology that has been perceived as an answer to enabling collaboration and knowledge transfer is Augmented Reality. AR can be described both as an information aggregator and a data publishing platform that allows the user to: 1) passively view displayed information; 2) actively engage and interact with published content; and 3) collaborate with others in real time from remote locations (Nassereddine et al., 2019). The capabilities of AR extend beyond visualization to include: analytical (improving the analysis of information and decision making); tracking (closely monitoring status); informational

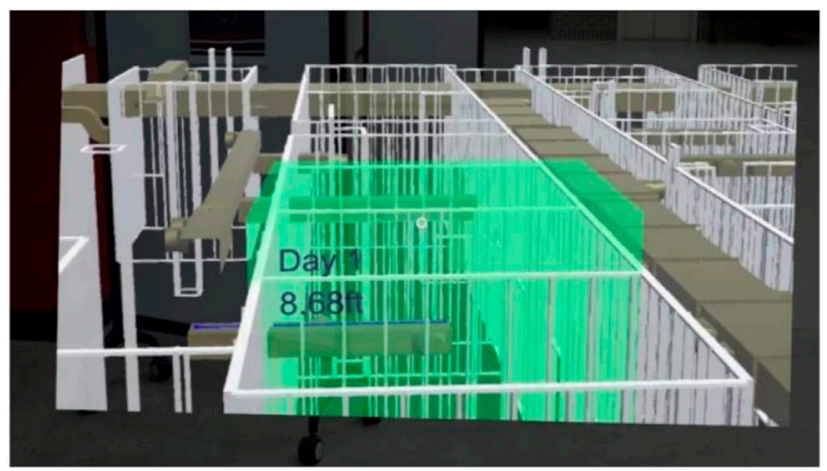

FIGURE 5 | Creation of measurements and production areas in the AR environment. Reprinted from Nassereddine (2019), fig. 73, p. 218.

(capturing process innovation for purposes of understanding); geographical (coordinating processes across distances); integrative (coordinating between tasks and processes); sequential (changing process sequence and enabling parallelization); automating (reducing human labor from the process); disintermediating (eliminating intermediaries from a process); and intellectual (capturing and distributing intellectual assets) (Nassereddine, 2019). AR is a technology that can be integrated throughout the lifecycle of the construction project (Nassereddine, 2019; Nassereddine et al., 2020b; Nassereddine et al., 2020c, Nassereddine et al., 2021). Two AR use-cases that the authors have previously explored will be discussed next to showcase how AR can help build resilience.

In Nassereddine et al. (2019), Nassereddine et al. (2020d), and Nassereddine (2019) the authors envisioned an AR-enabled production strategy process (PSP). PSP is an informationintensive process that enables the project to practice the execution of construction operations and identify potential problem areas before an execution phase begins. In a traditional setup, PSP uses physical copies of blueprints and requires the project team to be available in the same space to coordinate the production planning effort. The capabilities and benefits of the AR-enabled PSP were illustrated by developing a prototype for the HoloLens 1. Using a BIM model from a realworld construction project, the prototype was implemented on a healthcare project. The first view the user saw when they wore the HoloLens was a 3D model and the main menu of the application as displayed in Figure 4. The user perceived herself walking through the model and moving closer to the different systems and elements. The main menu comprised an interactive canvas that included various functions that the user could select. The main menu guided the user through the steps of PSP. For instance, the user could make virtual measurements and define production areas as illustrated in Figure 5. The validation of the prototype showed that all nine AR capabilities had a medium-to-high impact on PSP. Additionally, users reported that the technology enhanced their cognitive understanding of the process, facilitated decision-making, provided them with needed and desired information, and allowed a natural way to interact with the displayed information. Although not included in 


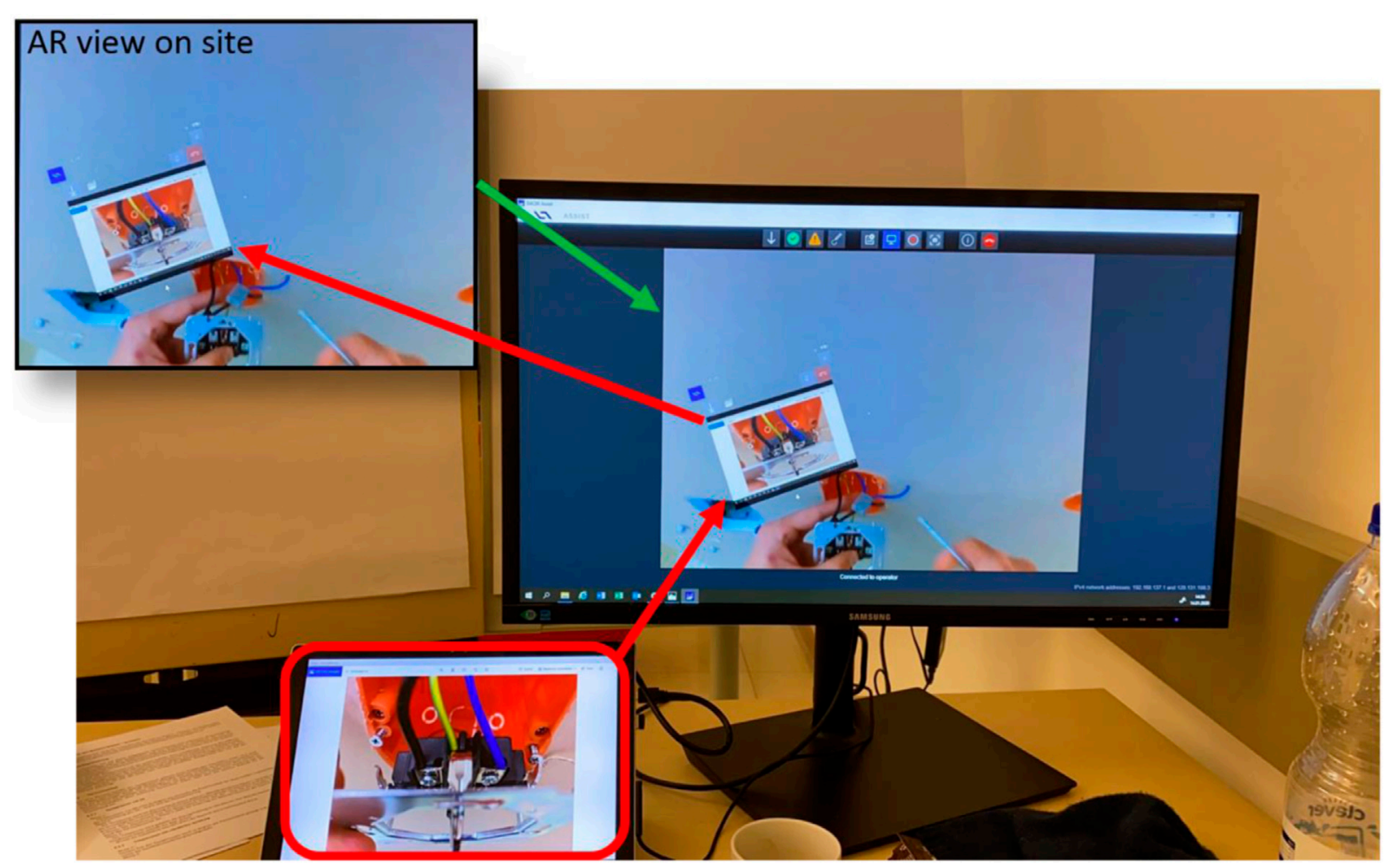

FIGURE 6 | Remote site inspection with Remote Expert System. Reprinted from Schranz et al. (2020), fig. 3, p. 382.

this prototype, the collaborative feature of the HoloLens enabled multiple users to remotely exist in the same environment and collaboratively develop a production plan. In a crisis such as the COVID-19 pandemic, AR delivers a solution to build resilience into construction projects to support the work of project team members without interruptions.

In Nassereddine et al. (2020a) and Schranz et al. (2020), the authors presented a remote expert system which worked with head-mounted displays, such as Daqri Smart Glasses or Microsoft HoloLens 2. The system included video telephony with a sitecompatible tracking system (Urban et al., 2020) and the possibility of inserting markers into a live image. It offered all of the above-mentioned advantages, the largest being the possibility to collaborate with others in real time from a remote location with constant access to information. Collaboration works well within and across multiple disciplines (crafts/trades). This is especially useful because workers of several disciplines tend to work simultaneously on a construction site.

Figure 6 shows the functionality of a remote expert system. The actual location of the remote expert is independent of the construction site and could be at a company office or even in the home of an employee. The latter would be ideal during a pandemic as stay-at-home orders became commonplace across the globe during COVID-19. Field personnel wear AR glasses and transmit their field of view to a remote expert. The tracking system of AR glasses are also used to create a $3 \mathrm{D}$-model of the surroundings. The main computer monitor shows the software of the remote expert system. The view of a field personnel is situated in the upper left corner. This view is transferred to the computer of the remote expert or that of several remote experts. The remote expert is therefore able to see what the field personnel with the head-mounted display sees, enabling him to give instructions and advice to the on-site personnel. Moreover, the remote expert can project pictures, manuals, data, or drawings onto the view of the AR device which is then shown in the head-mounted display of the field personnel. As an additional option, the remote expert can switch between a first-person view and a third-person view. The first-person view is the one shown in the Figure 6. A thirdperson view (not-shown in Figure 6) depicts the 3D model within its surroundings and gives the remote expert an overview of the situation of the project on-site in the vicinity of the field personnel wearing the AR glasses.

In other words, augmented reality gives workers additional access to information and the opportunity for enhanced collaboration. This supports decision making on-site, promoting the resilience of the workforce.

While AR offers various use-cases to support construction team members and build in resilience, it is important to note that this technology, as well as other Construction 4.0 technologies, does not operate completely independently. Both electricity and internet systems are critical for the reliable operation of Construction 4.0 technologies. The application of these technological innovations becomes challenging in off-grid places where access to electricity and the internet is limited. The massive winter storm that struck the utility grid of the state of 


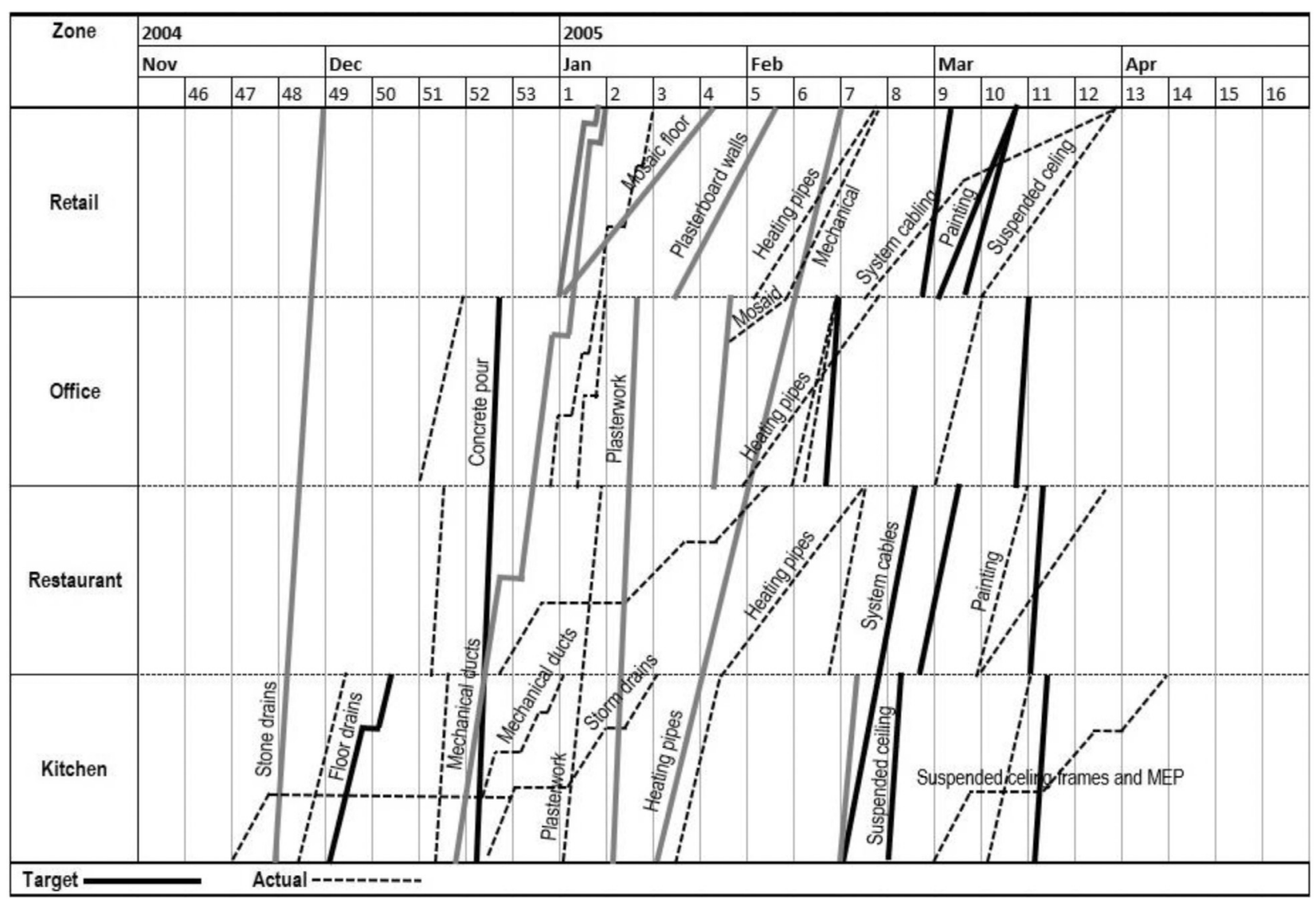

FIGURE 7 | LOB makes visible activity conflicts which is crucial when making decisions about where and when to prioritize application of automation and robotics. Adapted from Kenley and Seppanen (2010), Fig 17.10, p. 534.

Texas in February 2021 offers one example of why Construction 4.0 technologies should be considered as a supporting actor rather than as a sole actor.

\section{Automation and 3D Printing}

To survive and thrive, a construction company must have the capacity to respond effectively to changing external conditions. For example, a number of developed countries report ongoing shortages in skilled craft labor (McKinsey Global Institute, 2017). This shortage can be exacerbated in times of a pandemic where there is also a preference for social distancing and remote working. By contrast, technology in the form of construction robotics and automation offers a sanitized job site where, for example, the site for a farm of wind turbines in a rural location can be levelled and foundations bored using autonomous bulldozers, excavators, and compactors, controlled by operators working remotely and conveniently from their suburban homes (Bock, 2015; Azar and Kamat, 2017). Similarly, airborne drones and ground-based quadruped robots mounted with 360 scanners for 3D imagery/reality that capture applications can now fly over a site (drones) or nimbly climb over bull rocks, ascend and descend stairs (robots), and circulate along the exact same path repeatedly on a regular basis, substantially eliminating the variability and progress documentation errors that typically accompany human operators (Turkan et al., 2012). Not only is the external environment changing, there are heightening cultural expectations in what constitutes safe working conditions. Human exoskeletons can substantially enhance the strength of an on-site worker, while buffering him or her from commonly experienced muscle strain (Bock et al., 2011; Zhu et al., 2021). Large scale 3D-printing can and does additively erect the walls of a house while consuming a fraction of the time and labor it takes to build traditionally (Tay et al., 2017). Of course, multiple challenges still need to be addressed to make these systems fully practical and to operate smoothly; there are substantial gaps that need to be tackled in the development of the technology, but also in terms of improving the humantechnology interface (Dadhich et al., 2016; Czarnowski et al., 2018). Nevertheless, a number of construction companies are actively investing resources and collaborating to make these systems feasible (NEXT Coalition n.d.).

\section{Lean Construction}

Adaptation to changing conditions also demands a cultural framework that is receptive to-and even motivated by-the need to embrace change. 
The elements that comprise lean construction have been shown to help project teams effectively adopt technology which in turn, can facilitate adaptation when conditions have changed. An in-depth description of the four components of lean construction - to reduce waste and add value, using continuous improvement in a culture of respect-are beyond the scope of this paper, but in essence, if all four principles are effectively implemented a truly lean project site would exhibit the steady flows typically observed along a manufacturing assembly line (Hopp and Spearman, 2011; Rybkowski et al., 2013). The difference is that in manufacturing the actors are stationery and the product being created moves while on a construction site the actors (workers) are the ones moving through predefined areas of a stationery job site as they transform it.

One approach to tackling challenges to flow is through appropriate applications of automation and robotics. Not all processes may benefit from automation and robotics, while others most likely will. Discernment of these differences can be viewed through the lens of Lean-IPD (Integrated Project Delivery; Tzortzopoulos et al., 2020). Informed by advances in lean manufacturing where the velocities of individual activities are made explicit so they can be adjusted to achieve parallel flows visible on a line-of-balance (LOB) flow chart, an LOB schedule helps a team identify preceding flows that are creating bottlenecks for succeeding activities and therefore need removal or adjustments to enhance their velocities (Kenley and Seppanen, 2010; Pasquire, 2012; Rybkowski and Forbes, 2016; Figure 7). Lean projects have been shown to not only offer measurable improvements in the proverbial three-legged stool of time, cost, and quality, but in safety and morale as well.

Emerging systems of AI (artificial intelligence) can help a company collect and identify frequently occurring patterns of constraints of each activity so the efficiency of an entire system can be analyzed. A truly lean project is observable through observed parallel flows on LOB charts. Visualizing these flows-and interruptions to them-enables companies to collectively make prudent decisions about which forms of technology should be prioritized when external conditions change, so that bottlenecks are made clear, can be systematically unblocked, and a project can once again experience a state of steady flow.

\section{DISCUSSION AND CONCLUSION}

In an increasingly volatile, uncertain, complex, and ambiguous world, resilience in the face of change becomes a core competence of organizations working within the AEC industry. While a range of definitions of resilience has been used across disciplines, this paper defines resilience as the adaptive capacity of AEC organizations to survive and thrive in a changing environment. The COVID-19 pandemic is challenging the AEC industry to an extent unprecedented in recent history, reinforcing the need for organizations to build in resilience. Recognizing this need, the authors provided a bird's-eye view of the resilient future of the AEC industry, post-COVID-19 pandemic. First, the authors discussed embedding resilience as a strategy to create opportunities for AEC organizations to grow and secure business success in a changing environment. Next, resilience was discussed in the context of design, addressing specific needs of the A/E component of the AEC industry, and a set of trends that promote building resilience in design were highlighted. Then, a discussion of resilience in construction was presented to provide construction team members with practices to adapt and support the continuity of construction operations. Through a review and discussion of relevant literature, eleven trends related to the post-COVID-19 pandemic were proposed in Table 1. They are: 1) Portfolio diversification, 2) Collaborative contracting methods, 3) Industrialization, 4) Circular economy, 5) Remote working, 6) Integrated Design Management using BIM, 7) Staffing and skills training, 8) Reversible building design, 9) Augmented reality, 10) Automation and 3D printing, and 11) Lean construction.

While the eleven formulated propositions provide construction companies impetus to deal with the consequences of the COVID-19 pandemic, the authors recognize that building resilience in the AEC industry is a holistic and complex process. Under the traditional AEC model, silos and fragmentation are a natural outcome stemming from the nature of the industry. Design and construction firms are characterized as rigid, centralized organizations that follow a "command-andcontrol" structure (Wang and Du, 2011). These inherent traits of the industry result in a breakdown in communication, cooperation, and coordination and in an inefficient, asymmetric transfer of information among stakeholders, impeding organizational resilience (Fenwick et al., 2009). Researchers have noted that the internal and external structures of organizations can support and enable resilience (Andersson et al., 2019). A key structural contributor to resilience is decentralization (Tierney, 2008; Tengblad and Oudhuis, 2018; Andersson et al., 2019). Decentralization means power distribution allowing stakeholders at various levels to be responsible and accountable for the survival of the organization (Andersson et al., 2019). This decentralization is said to amplify the ability to adapt and improve (Kirchhof, 2020), but it cannot operate without integrated control of data shared by stakeholders involved in the project. The greater the need to socially distance because of the pandemic and therefore work in a distributed fashion, the greater is the need for a remotely accessible, digital, single source of truth, such as a shared BIM model. The authors' vision of a resilient, post-COVID-19 future for the AEC industry, illustrated in Figure 8, is built on two key components: decentralization of workforce, and integration of data.

The eleven propositions of building resilience in the AEC industry are embodied in the proposed decentralized model in Figure 8: 1) Portfolio diversification leads to decentralization of the operations of design and construction firms. This decentralization can shield companies from the risk of "putting all eggs in one basket;" 2) The early involvement of key project participants promoted through the use of collaborative contracting methods provides a decentralized source of innovative ideas. Forming direct relationships between stakeholders addresses the vertical and longitudinal fragmentation of AEC companies; 3) Industrialized construction crosses traditional 

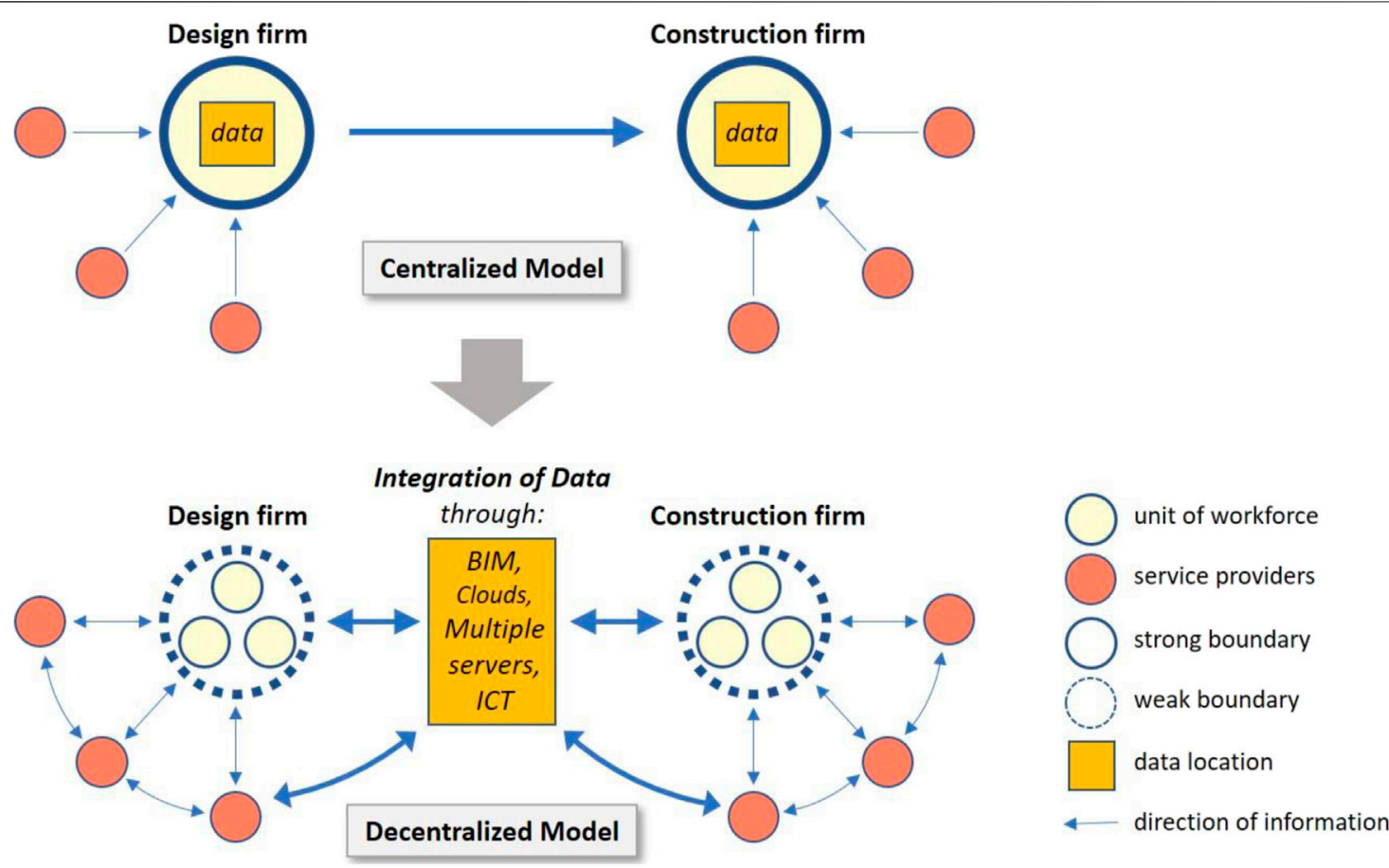

FIGURE 8 | Decentralization of workforce and integration of data.

supply chain boundaries and introduces new player to the supply chain; 4) Circular business models challenge the traditional centralized model of the AEC industry as a circular economy implies more decentralized production processes to reuse and recycle materials; 5) Remote working is expected to become a major option for any company and this will transform the former centralized model into working to a distributed model; 6) Integrated design management using BIM enables a centralized control of data throughout the whole process of the project, allowing fast and efficient decision-making between design firms, construction firms and service providers; 7) Resilience in staffing and skills trainings is a crucial investment for business continuity by means of decentralized management of multiple workforce units and liaising with external firms and service providers; 8) Reversible Building Design can only guarantee success through re-distribution of knowledge and expertise between stakeholders who are dedicated to the common goal of recycling building materials; 9) AR-enabled applications act as both a centralized reference that encompasses the different type of information and data needed by stakeholders and a decentralized decision-making tool that empowers stakeholder and improves cooperative work through augmented reality; 10) The shift to automation and 3D printing allows new non-construction actors to enter the construction market to provide the needed technology and expertise; 11) Lean Construction provides additional flexibility to construction stakeholders, decentralizes decision-making, enhances flow of information among stakeholders, increases conversation and dialogue between project participants, and leverages the use of BIM.

Finding the desired equilibrium between the traditional and proposed model is critical. The structure of design and construction firms should be designed to fit emerging circumstances rather than through pre-determination. This paper provides practitioners and researchers with a glimpse into the future of the AEC industry post-pandemic where resilience is essential to offset disruptions and enable the survival and growth of AEC organizations. This discussion on resilience can be extended to other stakeholders in the construction supply chain. Additionally, the work presented in this paper is conceptual and will be expanded on in future work through case studies with design and construction firms.

\section{DATA AVAILABILITY STATEMENT}

The original contributions presented in the study are included in the article/supplementary material, further inquiries can be directed to the corresponding authors.

\section{AUTHOR CONTRIBUTIONS}

All listed authors have made a substantial, direct, and intellectual contribution to the content of this paper.

\section{FUNDING}

The authors acknowledge the TU Wien Bibliothek for financial support through its Open Access Funding Program. 


\section{REFERENCES}

Adhikari, K., and Poudyal, L. (2021). Future of Construction Industry: COVID-19 and its Implications on Construction Projects and Risk Management-A Review. AIA (2020). Architect's Guide to Business Continuity: Guidance for Reducing Firm Disruption. Washington: The American Institute of Architects. Available at: http://content.aia.org/sites/default/files/2020-03/Architects-Guide-to-BusinessContinuity.pdf?utm_medium $=$ website\&utm_source=archdaily (February 5, 2021).

AIA (2017). Disaster Assistance Handbook. Third Edition. The American Institute of Architects.

AIA (2007). Integrated Project Delivery: A Guide. The American Institute of Architects.

Al Sayegh, N. K. (2010). The Impact of Diversification Strategy on the Construction Organisations Corporate Level Performance. PhD Thesis. Dubai: The British University in Dubai (BUiD).

Alsharef, A., Banerjee, S., Uddin, S. M. J., Albert, A., and Jaselskis, E. (2021). Early Impacts of the COVID-19 Pandemic on the United States Construction Industry. Ijerph 18 (4), 1559. doi:10.3390/ijerph18041559

Andersson, T., Cäker, M., Tengblad, S., and Wickelgren, M. (2019) Building Traits for Organizational Resilience through Balancing Organizational Structures. Scand. J. Manage., 35., 36-45. doi:10.1016/j.scaman.2019.01.001

Angeler, D. G., and Allen, C. R. (2016). Quantifying Resilience. J. Appl. Ecol. 53, 617-624. doi:10.1111/1365-2664.12649

Araya, F. (2021). Modeling the Spread of COVID-19 on Construction Workers: An Agent-Based Approach. Saf. Sci. 133, 105022. doi:10.1016/j.ssci.2020.105022

Arayici, Y., Egbu, C., and Coates, P. (2012). Building Information Modelling (BIM) Implementation and Remote Construction Projects: Issues, Challenges, and Critiques. J. Inf. Tech. Construction 17, 75-92.

A. Sawhney, M. Riley, and J. Irizarry (Editors). Construction 4.0 - an Innovation Platform for the Built Environmen.(London: Routledge).

Astrachan, I.-D. (2020). Modular Construction as a Post COVID-19 Design Alternative. Available at: https://www.buildingenclosureonline.com/articles/ 89199-modular-construction-as-a-post-covid-19-design-alternative?v=preview (Mar, 10 2021).

Azar, E. R., and Kamat, V. R. (2017). Earthmoving Equipment Automation: A Review of Technical Advances and Future Outlook. J. Inf. Tech. Construction 22, 247-265.

Barbosa, F., Bresciani, G., Graham, P., Nyquist, S., and Yanosek, K. (2020). Oil and Gas after COVID-19: The Day of Reckoning or a New Age of Opportunity, 15. Houston: McKinsey \& Company, 2020.

Belhadi, A., Mani, V., Kamble, S. S., Khan, S. A. R., and Verma, S. (2021). Artificial Intelligence-Driven Innovation for Enhancing Supply Chain Resilience and Performance under the Effect of Supply Chain Dynamism: an Empirical Investigation. Basingstoke: Annals of Operations Research, Springer. doi:10.1007/s10479-021-03956-x

Birkinshaw, J., Cohen, J., and Stach, P. (2020). Knowledge Workers Are More Productive from Home. 2020. Available at: https://hbr.org/2020/08/researchknowledge-workers-are-more-productive-from-home (Mar. 10, 2021).

Bock, T., Linner, T., and Ikeda, W. (2011). "Exoskeleton and Humanoid Robotic Technology in Construction and Built Environment," in The Future Of Humanoid Robots - Research And Applications. Editor R. Zaier (Amsterdam: InTechCorp), 111-146.

Bock, T. (2015). The Future of Construction Automation: Technological Disruption and the Upcoming Ubiquity of Robotics. Automation in Construction 59, 113-121. doi:10.1016/j.autcon.2015.07.022

Bou Hatoum, M., Piskernik, M., and Nassereddine, H. (2020). "A Holistic Framework for the Implementation of Big Data throughout a Construction Project Lifecycle," in Proceedings of the 37th International Symposium on Automation and Robotics in Construction (ISARC). Editors H. Osumi, H. Furuya, and K. Tateyama (Kitakyushu, Japan: International Association for Automation and Robotics in Construction (IAARC)), 1299-1306.

Build Media Group (2021). Management Trends Emerging in the Construction Industry Due to COVID-19 Pandemic. Toronto: For Construction Pros. Available at: https:/www.forconstructionpros.com/business/constructionsafety/article/21342920/build-media-group-management-trends-emerging-in-theconstruction-industry-due-to-covid19-pandemic (Apr 24, 2021).
Butler, C. (2018). Five Steps to Organisational Resilience: Being Adaptive and Flexible during Both normal Operations and Times of Disruption. J. business continuity Emerg. Plann. 12 (2), 103-112.

Buxton, P. (2020). Home Working? We're Doing it Already. London: The Royal Institute of British Architects.

Byrne, E. (2020). Post-pandemic Construction: Could COVID-19 Be the Catalyst for Digital Adoption?. Available at: http://constructionexec.com/article/postpandemic-construction-could-covid-19-be-the-catalyst-for-digital-adoption (May 4, 2021).

Çetin, S., Gruis, V., and Straub, A. (2021). Towards Circular Social Housing: An Exploration of Practices, Barriers, and Enablers. Sustainability 13, 2100 doi:10.3390/su13042100

Cheshmehzangi, A. (2021). Revisiting the Built Environment: 10 Potential Development Changes and Paradigm Shifts Due to COVID-19. J. Urban Manage. 10 (2), 166-175. doi:10.1016/j.jum.2021.01.002

Chong, E., Handscomb, C., Williams, O., Hall, R., and Rooney, M. (2020). “Agile Resilience in the UK: Lessons from COVID-19 for the 'next normal. Available at: https://www.mckinsey.com/business-functions/organization/our-insights/ agile-resilience-in-the-uk-lessons-from-covid-19-for-the-next-normal (Feb 22, 2021).

Clough, R. H., Sears, G. A., and Sears, S. K. (2008). Construction Project Management: A Practical Guide to Field Construction Management. New Jersey: Wiley.

Cooke, F. L., Wood, G., Wang, M., and Li, A. S. (2021). Riding the Tides of Mergers and Acquisitions by Building a Resilient Workforce: A Framework for Studying the Role of Human Resource Management. Hum. Resource Manage. Rev. 31, 100747. doi:10.1016/j.hrmr.2020.100747

Courtemanche, T. (2020). Make the Call for More Construction Technology in a Time of Crisis. Available at: https://www.enr.com/articles/49021-make-thecall-for-more-construction-technology-in-a-time-of-crisis (Feb 22, 2021) doi: $10.3386 /$ w2 26670

Crowther, P. (2005). "The State of Building Deconstruction in Australia," in Deconstruction and Material Reuse - an International Overview. Editor A.R. Chini (USA: Final Report of Task Group 39 on Deconstruction, CIB Publication, 300, University of Florida).

Cutieru, A. (2020). A Guide to Design for Disassembly. Available at: https://www. archdaily.com/943366/a-guide-to-design-for-disassembly (Mar 18, 2021).

Czarnowski, J., Dąbrowski, A., Maciaś, M., Główka, J., and Wrona, J. (2018). Technology Gaps in Human-Machine Interfaces for Autonomous Construction Robots. Automation in Construction 94, 179-190. doi:10.1016/ j.autcon.2018.06.014

Dadhich, S., Bodin, U., and Andersson, U. (2016). Key Challenges in Automation of Earth-Moving Machines. Automation in Construction 68 (August), 212-222. doi:10.1016/j.autcon.2016.05.009

Debacker, W., and Manshoven, S. (2016). D1 Synthesis of the State-Of-The-Art: Key Barriers and Opportunities for Materials Passport and Reversible Building Design in the Current System. Available at: www.bamb2020.eu/wpcontent/ uploads/2016/03/D1_Synthesis-report-on-State-of-the-art_20161129_FINAL. pdf (Mar,14 2021).

Desai, A. P. (2012). Exploring Crew Behavior during Uncertain Jobsite conditions. Master Thesis. Construction Management: Michigan State University.

Dokter, G., Thuvander, L., and Rahe, U. (2021). How Circular Is Current Design Practice? Investigating Perspectives across Industrial Design and Architecture in the Transition towards a Circular Economy. Sustainable Prod. Consumption 26, 692-708. doi:10.1016/j.spc.2020.12.032

Domingos, J. P., Oliveira, J. D., and Faria, F. S. (2021). "The Impact of Digital Transformation, Available at: https://www2.deloitte.com/ce/en/pages/realestate/articles/the-impact-of-digital-transformation-on-construction-companiesdiversified-strategy.html (Apr. 24, 2021).

Durmisevic, E. (2020). Super Circular Estate Project. J. No 4. Lille: Project led by the Municipality of Kerkrade, UIA (Urban Innovative Actions).

Ebekozien, A., and Aigbavboa, C. (2021). COVID-19 Recovery for the Nigerian Construction Sites: The Role of the Fourth Industrial Revolution Technologies. Sustain. Cities Soc. 69, 102803. doi:10.1016/ j.scs.2021.102803

El Jazzar, M., Piskernik, M., and Nassereddine, H. (2020a). Digital Twin in Construction: An Empirical Analysis. EG-ICE 2020 Proc. Workshop Intell. Comput. Eng., 501-510. 
El Jazzar, M., Urban, H., Schranz, C., and Nassereddine, H. (2020b). "Construction 4.0: A Roadmap to Shaping the Future of Construction in 2020 Proceedings of the 37th ISARC, Kitakyushu, Japan, 1314-1321.

Fenwick, T., Seville, E., and Brunsdon, D. (2009). Reducing the Impact of Organizational Silos on Resilience. New Zealand: Resilient Organizations Research Programme.

Fulco, I., La Sala, A., and Loia, F. (2019). "The Role of Technology for Building Resilience Thinking in Corporate Governance," in New Challenges in Corporate Governance: Theory and Practice. Editors S. Esposito De Falco, F. Alvino, and A. Kostyuk, 206-219.

Gatheeshgar, P., Poologanathan, K., Gunalan, S., Shyha, I., Sherlock, P., Rajanayagam, H., et al. (2021). Development of Affordable Steel-Framed Modular Buildings for Emergency Situations (Covid-19). Structures 31, 862-875. doi:10.1016/j.istruc.2021.02.004

Green, B. (2020). "What Will Happen to the Office? the Evidence." London: The Royal Institute of British Architects.

Hamma-adama, M., and Kouider, T. (2019). Comparative Analysis of BIM Adoption Efforts by Developed Countries as Precedent for New Adopter Countries. C. Jast 36 (2), 1-15. doi:10.9734/cjast/2019/v36i230224

Harrouk, C. (2020). Architecture post Covid-19: The Profession, the Firms, and the Individuals. Available at: https://www.archdaily.com/939534/architecturepost-covid-19-the-profession-the-firms-and-the-individuals (May 23, 2020).

Heiskanen, A. (2020). The Future of Construction Post COVID-19 - an Interview with Aarni Heiskanen. Helsinki: AEC Business. Available at: https://aecbusiness.com/the-future-of-construction-post-covid-19-an-interview-withaarni-heiskanen/(Apr 30, 2021). doi:10.5194/bg-2020-370-ac1

Holling, C. S. (1973). Resilience and Stability of Ecological Systems. Annu. Rev. Ecol. Syst. 4, 1-23. doi:10.1146/annurev.es.04.110173.000245

Hopp, W. J., and Spearman, M. L. (2011). Factory Physics. Long Grove, IL: Waveland Press.

Hosseini, S., Barker, K., and Ramirez-Marquez, J. E. (2016). A Review of Definitions and Measures of System Resilience. Reliability Eng. Syst. Saf. 145, 47-61. doi:10.1016/j.ress.2015.08.006

Ibn-Mohammed, T., Mustapha, K. B., Godsell, J., Adamu, Z., Babatunde, K. A., Akintade, D. D., et al. (2021). A Critical Analysis of the Impacts of COVID-19 on the Global Economy and Ecosystems and Opportunities for Circular Economy Strategies. Resour. Conservation Recycling 164, 105169. doi:10.1016/j.resconrec.2020.105169

International Labour Organization (2021). Impact of COVID-19 on the Construction Sector. Availabel at: http://www.ilo.org/sector/Resources/ publications/WCMS_767303/lang-en/index.htm (Apr 24, 2021).

Jaillon, L., Poon, C. S., and Chiang, Y. H. (2009). Quantifying the Waste Reduction Potential of Using Prefabrication in Building Construction in Hong Kong. Waste Manage. 29, 309-320. doi:10.1016/ j.wasman.2008.02.015

Jaillon, L., and Poon, C. S. (2014). Life Cycle Design and Prefabrication in Buildings: A Review and Case Studies in Hong Kong. Automation in Construction 39, 195-202. doi:10.1016/j.autcon.2013.09.006

Jones, K. (2020). How the Construction Industry Will Change Due to COVID-19. Availabel at: https://www.constructconnect.com/blog/how-the-constructionindustry-will-change-due-to-covid-19 (Feb 28, 2021).

Juhasz, R., Squicciarini, M. P., and Voigtlander, N. (2020). Away from Home and Back: Coordinating (Remote) Workers in 1800 and 2020. Working Paper. Cambridge, MA: National Bureau of Economic Research. doi:10.3386/w28251

Kamble, S. S., Gunasekaran, A., and Gawankar, S. A. (2018). Sustainable Industry 4.0 Framework: A Systematic Literature Review Identifying the Current Trends and Future Perspectives. Process Saf. Environ. Prot. 117, 408-425. doi:10.1016/ j.psep.2018.05.009

Keenan, J. M. (2020). COVID, Resilience, and the Built Environment. Environ. Syst. Decis. 40, 216-221. doi:10.1007/s10669-020-09773-0

Kenley, R., and Seppanen, O. (2010). Location-Based Management for Construction: Planning, Scheduling, and Control. New York: Spon Press.

Kim, H.-J., and Reinschmidt, K. F. (2011). Diversification by the Largest US Contractors. Can. J. civil Eng. NRC Res. Press 38 (7), 800-810.

Kim, L. (1998). Crisis Construction and Organizational Learning: Capability Building in Catching-Up at Hyundai Motor. Organ. Sci. 9 (4), 506-521. doi:10.1287/orsc.9.4.506
Kirchhof, P. (2020). A Tale of Two Countries: How Decentralized Organization and Long-Term Investment Build Resilient Healthcare Systems. Eur. Heart Journal-Quality Care Clin. Outcomes 6 (3), 201-203. doi:10.1093/ehjqcco/ qcaa036

Kirkman, B., Stoverink, A. C., Mistry, S., and Rosen, B. (2019). The 4 Things Resilient Teams Do. Harv. Business Rev.. Available at: https://hbr.org/2019/07/ the-4-things-resilient-teams-do (March 20, 2021).

Klinc, R., and Turk, Ž. (2019). Construction 4.0 - Digital Transformation of One of the Oldest Industries. Econ. Business Rev. 21 (No. 3), 393-410.

Kozminska, U. (2019). Circular Design: Reused materials and the future reuse of building elements in architecture. Process, challenges and case studies. IOP Conf. Series Earth Environ. Sci. 225, 012033. doi:10.1088/1755-1315/225/1/ 012033

Kurth, M. H., Keenan, J. M., Sasani, M., and Linkov, I. (2019). Defining Resilience for the US Building Industry. Building Res. Inf. 47 (4), 480-492. doi:10.1080/ 09613218.2018.1452489

Laing, A., and Moss, A. (2020). Potential Changes in Office, Retail, and Residential Construction in the Post-COVID-19 Market. Available at: https://www.jdsupra. com/legalnews/potential-changes-in-office-retail-and-27805/ (Mar 26, 2021).

Leon, I., Sagarna, M., Mora, F., and Otaduy, J. P. (2021). BIM Application for Sustainable Teaching Environment and Solutions in the Context of COVID-19. Sustainability 13, 4746. doi:10.3390/su13094746

Lowery, D., Wright, E., and Ijeh, I. (2011). Architects and Recession: Battered, Bruised and Broke. Available at: https://www.building.co.uk/focus/architectsand-recession-battered-bruised-andbroke/5012558.article (Feb 21, 2021).

Luo, H., Liu, J., Li, C., Chen, K., and Zhang, M. (2020). Ultra-rapid Delivery of Specialty Field Hospitals to Combat COVID-19: Lessons Learned from the Leishenshan Hospital Project in Wuhan. Automation in Construction 119, 103345. doi:10.1016/j.autcon.2020.103345

Markowitz, H. (1959). Portfolio Selection, Efficient Diversification of Investments. J. Wiley.

Matthews, O., and Howell, G. A. (2005). Integrated Project Delivery an Example of Relational Contracting. Lean construction J. 2 (1), 46-61.

Mcaa (2020). Southland Industries Uses Integrated Project Delivery to Speed Delivery of COVID-19 Facility. Rockville, MD: Mechanical Contractors Association of America.

McKinsey and Company (2020a). Covid-19: Briefing Materials. Updated July 6th, 2020. https://www.mckinsey.com/ /media/mckinsey/business\%20functions/ risk/our\%20insights/covid\%2019\%20implications\%20for\%20business/covid\% 2019\%20july\%209/covid-19-facts-and-insights-july-6.pdf (Mar 21, 2021).

McKinsey and Company (2020b). How COVID-19 Has Pushed Companies over the Technology Tipping point - and Transformed Business Forever. https:// www.mckinsey.com/business-functions/strategy-and-corporate-finance/ourinsights/how-covid-19-has-pushed-companies-over-the-technology-tippingpoint-and-transformed-business-forever (Mar 13, 2021).

McKinsey and Company (2020c). The Next normal in Construction: How Disruption Is Reshaping the World's Largest Ecosystem.

McKinsey Global Institute (2017). Reinventing Construction: A Route to Higher Productivity, 155.

Meisels, M. (2020). Deloitte: Contractors Can Combat COVID-19 Crisis with Resilience. Available at: https://www.enr.com/articles/49665-deloittecontractors-can-combat-covid-19-crisis-with-resilience (Mar 6, 2021).

Miller, G. T., and Spoolman, S. E. (2009). Sustaining the Earth. Australia: Brooks/ Cole, Cengage Learning.

Mirza, A. (2020). Workload Lessons from Past Recessions. London: RIBA J. Available at: https://www.ribaj.com/intelligence/architects-workloadlessons-from-past-recessions-coronavirus (Feb 21, 2021).

Morris, N. (2021). "Working Remotely with Colleagues and clients." Amsterdam: RIBA Architecture com. Available at: https://www.architecture.com/ knowledge-and-resources/knowledge-landing-page/working-remotely-withcolleagues-and-clients (Feb 17, 2021).

Munaro, M. R., Tavares, S. F., and Bragança, L. (2020). Towards Circular and More Sustainable Buildings: A Systematic Literature Review on the Circular Economy in the Built Environment. J. Clean. Prod. 260, 121134. doi:10.1016/ j.jclepro.2020.121134

Myer, B. (2020). How a Global Construction Company Is Cultivating Resilience in the Time of Covid-19 - Triangle Business Journal. 
Available at: https://www.bizjournals.com/triangle/news/2020/11/17/constructioncompany-is-cultivating-resilience.html (Mar 30, 2021).

Nassereddine, H., El Jazzar, M., and Piskernik, M. (2020a). "Transforming the AEC Industry: A Model-Centric Approach," in Creative Construction e-Conference 2020 (Budapest: Budapest University of Technology and Economics), 13-18.

Nassereddine, H., Hanna, A. S., and Veeramani, D. (2020b). Augmented Reality in the Construction Industry: An Industry's Perspective of its Users, Phases, and Future Trends Construction Research Congress 2020: Computer Applications. VA: American Society of Civil Engineers Reston, 743-752.

Nassereddine, H., Lotfallah, W., Hanna, A., and Veeramani, D. (2020c). "Development of an Augmented Reality Fitness Index for Contractors," in Proceedings of the 37th International Symposium on Automation and Robotics in Construction (ISARC). Editors H. Osumi, H. Furuya, and K. Tateyama (Kitakyushu, Japan: International Association for Automation and Robotics in Construction (IAARC)), 40-47.

Nassereddine, H. M. (2019). Design, Development and Validation of an Augmented Reality-Enabled Production Strategy Process for the Construction Industry. The University of Wisconsin-Madison. Ph.D. Thesis. doi:10.22260/isarc2019/0040

Nassereddine, H., Veeramani, A., and Veeramani, D. (2021). "Exploring the Current and Future States of Augmented Reality in the Construction Industry," in Collaboration And Integration In Construction, Engineering, Management And Technology (Springer), 185-189. doi:10.1007/978-3-03048465-1_31

Nassereddine, H., Veeramani, D., and Hanna, A. (2019). Augmented RealityEnabled Production Strategy Process. Proc. 36th Int. Symp. Automation Robotics Construction (Isarc), 297-305.

Nassereddine, H., Veeramani, D., and Hanna, A. (2020d). "The Impact of Integrating Augmented Reality into the Production Strategy Process," in Proceedings of the 37th International Symposium on Automation and Robotics in Construction (ISARC). Editors H. Osumi, H. Furuya, and K. Tateyama (Kitakyushu, Japan: International Association for Automation and Robotics in Construction (IAARC)), 1160-1167.

NBS (2020). 10th Annual BIM Report. Newcastle Upon Tyne: NBS Enterprises Ltd.

Nelson, D. R., Adger, W. N., and Brown, K. (2007). Adaptation to Environmental Change: Contributions of a Resilience Framework. Annu. Rev. Environ. Resour. 32, 395-419. doi:10.1146/annurev.energy.32.051807.090348

NEXT Coalition n.d. Available at: https://nextcoalition.co/ (March 20, 2021).

Ojansivu, I. T., and Hermes, J. (2019). "Maintaining Business Relationships: Resilience through Institutional Work." J. Business Ind. Marketing. doi:10.1108/JBIM-05-2019-0260

Pasquire, C. (2012). "The $8^{\text {th }}$ Flow-Common Understanding," in Proceedings of the 20th Annual Conference of the International Group of Lean Construction San Diego, CA USA.

Potting, J., Hekkert, M., Worrell, E., and Hanemaaijer, A. (2017). Circular Economy: Measuring Innovation in the Product Chain. The Hague: PBL Netherlands Environmental Assessment Agency.

Rajabi, S., and Bheiry, S. (2020). Portfolio Management for Construction Company during Covid-19 Using AHP Technique. Int. J. Ind. Syst. Eng. 14 (11), 1053-1063.

Ralston, P., and Blackhurst, J. (2020). Industry 4.0 and Resilience in the Supply Chain: a Driver of Capability Enhancement or Capability Loss?. Int. J. Prod. Res. 58 (16), 5006-5019. doi:10.1080/00207543.2020.1736724

Ramya, G. (2020). "Overcoming the Impact of COVID-19 Using Integrated Project Delivery Model.”

Riba (2019). RIBA: Code of Practice. Available at: https://www.architecture.com/-/ media/GatherContent/Test-resources-page/Additional-Documents/RIBA-Codeof-Practice-May-2019pdf.pdf (Feb 13, 2021).

Riba (2020a). "How to Ensure Business Continuity during lockdown." the RIBA Recovery Roadmap Phase 1Available at: https://www.architecture. $\mathrm{com} /$ knowledge-and-resources/knowledge-landing-page/how-to-ensurebusiness-continuity-during-lockdown (Feb 09, 2021).

Riba (2020b). How to Develop Your Recovery plan." the RIBA Recovery Roadmap Phase. Available at: https://www.architecture.com/knowledge-and-resources/ knowledge-landing-page/developing-a-recovery-plan (Feb 09, 2021).
Riba (2020c). How to Win New work." the RIBA Recovery Roadmap Phase. Available at: https://www.architecture.com/knowledge-and-resources/ knowledge-landing-page/how-to-win-new-work (Feb 09, 2021).

Rubin, D., Buckley, B., Berardi, E., and Yoders, J. (2021). A Resilient Workforce Triumphs through a Tough 2020. Available at: https://www.enr.com/ articles/51043-a-resilient-workforce-triumphs-through-a-tough-year (Feb 22, 2021).

Rybkowski, Z. K., Abdelhamid, T., and Forbes, L. (2013). "On the Back of a Cocktail Napkin: An Exploration of Graphic Definitions of Lean Construction," in Proceedings of the 21st Annual Conference for the International Group for Lean Construction (Brazil: Fortaleza), 83-92.

Rybkowski, Z. K., and Forbes, L. (2016). "Chapter 8: Lean Construction," in Handbook Of Construction Management: Scope, Schedule, and Cost Control. Editor A. Razzak Rumane (Florida: CRC Press Taylor \& Francis Group).

Schranz, C., Gerger, A., and Urban, H. (2020). Augmented Reality im Bauwesen: Teil 1 - Anwendungs- und Anforderungsanalyse/Augmented Reality in civil engineering: Part 1 - Use-case and requirement analysis. Bauingenieur 95 (10), 379-388. doi:10.37544/0005-6650-2020-10-49

Snyder, J. (2020). The Role of Construction Technology in COVID-19 Recovery. Available at: https://www.fminet.com/fmi-quarterly/article/2020/06/the-roleof-construction-technology-in-covid-19-recovery/ (Feb 22, 2021).

Souza, E. (2021). Lightwight \& Detachable Solutions: Building as a Reserve of Materials for the Future. Available at: https:/www.archdaily.com/951050/ lightweight-and-detachable-solutions-buildings-as-a-reserve-of-materials-forthe-future?utm_medium=email\&\%E2\%80\%A6 (Feb 22, 2021).

Succar, B. (2009). Building Information Modelling Framework: a Research and Delivery Foundation for Industry Stakeholders. Automation in Construction 18 (3), 357-375. doi:10.1016/j.autcon.2008.10.003

Tay, Y. W. D., Panda, B., Paul, S. C., Noor Mohamed, N. A., Tan, M. J., Leong, K. F., et al. (2017). 3D Printing Trends in Building and Construction Industry: a Review. Virtual Phys. Prototyping 12, 261-276. doi:10.1080/ 17452759.2017.1326724

Tengblad, S., and Oudhuis, M. (2018). The Resilience Framework. Springer.

The Economist (2020). Work-life Balance, 17-18. London: Union slack.

The Fees Bureau (2020). Architects Markets. Mirza \& Nacey Research Ltd.

Tierney, K. (2008). Structure and Process in the Study of Disaster Resilience in Proceedings of the 14th world conference on earthquake engineering (Beijing, China: . CAEE).

Tokazhanov, G., Tleuken, A., Guney, M., Turkyilmaz, A., and Karaca, F. (2020). How Is COVID-19 Experience Transforming Sustainability Requirements of Residential Buildings? A Review. Sustainability 12 (20), 8732. doi:10.3390/ su12208732

Trimble Buildings (2020). Digital Resilience in Construction: Industry Leaders and Analysts Explain How to Thrive in the New Economy.

Turkan, Y., Bosche, F., Haas, C. T., and Haas, R. (2012). Automated Progress Tracking Using 4D Schedule and 3D Sensing Technologies. Automation in Construction 22, 414-421. doi:10.1016/j.autcon.2011.10.003

Tzortzopoulos, P., Kagioglou, M., and Koskela, L. (2020). Lean Construction: Core Concepts and New Frontiers. London: RoutledgeTaylor \& Francis.

Urban, H., Irschik, T., Schranz, C., and Schönauer, C. (2020). Augmented Reality im Bauwesen: Teil 2 - Baustellentaugliches Trackingsystem/ Augmented Reality in Civil Engineering: Part 2 - site-compatible tracking system. Bauingenieur 95 (12), 501-508. doi:10.37544/00056650-2020-12-67

Wallett, P. (2021). "The Impact of COVID: How Automation Helps Rebuild the Construction Industry. BW BusinessworldAvailable at: http://businessworld. in/article/The-Impact-Of-COVID-How-Automation-Helps-Rebuild-TheConstruction-Industry-/22-07-2020-300097 (May 4, 2021).

Wang, J., Cooke, F. L., and Huang, W. (2014a). How Resilient Is the (Future) Workforce in China? A Study of the Banking Sector and Implications for Human Resource Development. Asia Pac. J. Hum. Resour. 52 (2), 132-154. doi:10.1111/1744-7941.12026

Wang, Q., and Du, J. (2011). “A Scenario Simulation Study of Decentralization on Architecture, Engineering and Construction Companies," in Proceedings of the Engineering Project Organizations Conference (Estes Park, Colorado).

Wang, X., Truijens, M., Hou, L., Wang, Y., and Zhou, Y. (2014b). Integrating Augmented Reality with Building Information Modeling: Onsite Construction 
Process Controlling for Liquefied Natural Gas Industry. Automation in Construction 40, 96-105. doi:10.1016/j.autcon.2013.12.003

Wilkinson, S., Chang-Richards, A. Y., Sapeciay, Z., and Costello, S. B. (2016). Improving Construction Sector Resilience. Int. J. Disaster. drbe 7 (2), 173-185. doi:10.1108/ijdrbe-04-2015-0020

Wong, R., Fidler, C., and Singh, J. (2020). Strategic Considerations for New Projects. " Osler, Hoskin \& Harcourt LLP. Available at: http://www.osler.com/ en/blogs/construction/july-2020/strategic-considerations-for-new-projects (Apr 24, 2021).

Wood, L. (2021). South Africa Construction Industry Report 2020: Industry Performance, COVID-19 Impact, Influencing Factors, Industry Associations. GlobeNewswire News Room. Available at: https://www.globenewswire.com/ newsrelease/2021/03/24/2198258/28124/en/South-Africa-ConstructionIndustry-Report-2020-Industry-Performance-COVID-19-Impact-Influencing-FactorsIndustry-Associations.html (Apr 24, 2021).

Zawya (2021). Interview: COVID-19 Sharpens Focus on Resilience, Sustainability - Rockwell Automation Chief. Available at: https://www. zawya.com/mena/en/business/story/Interview_COVID19_sharpens_focus_on_ resilience_sustainability_Rockwell_Automation_Chief-ZAWYA20210114030345 (Feb 22, 2021).
Zhang, W. J., and Van Luttervelt, C. A. (2011). Toward a Resilient Manufacturing System. CIRP Ann. 60 (1), 469-472. doi:10.1016/j.cirp.2011.03.041

Zheng, L., Chen, K., and Ma, L. (2020). Knowledge, Attitudes, and Practices towards COVID-19 Among Construction Industry Practitioners in China. Front. Public Health Front. 8, 981. doi:10.3389/fpubh.2020.599769

Zhu, A., Dutta, A., and Dai, R. (2021). "Exoskeletons for Manual Material Handling-A Review and Implication for Construction Applications. Automation in Construction 122, 303493. doi:10.1016/j.autcon.2020.103493

Conflict of Interest: The authors declare that the research was conducted in the absence of any commercial or financial relationships that could be construed as a potential conflict of interest.

Copyright (c) 2021 Nassereddine, Seo, Rybkowski, Schranz and Urban. This is an open-access article distributed under the terms of the Creative Commons Attribution License (CC BY). The use, distribution or reproduction in other forums is permitted, provided the original author(s) and the copyright owner(s) are credited and that the original publication in this journal is cited, in accordance with accepted academic practice. No use, distribution or reproduction is permitted which does not comply with these terms. 